\title{
Molecular detection of tick-borne bacteria and protozoa in cervids and wild boars from Portugal
}

\author{
André Pereira ${ }^{1}$, Ricardo Parreira ${ }^{2,3}$, Mónica Nunes ${ }^{2,3}$, Afonso Casadinho ${ }^{1}$, Maria Luísa Vieira ${ }^{2,3}$, Lenea Campino ${ }^{2,4,5}$ \\ and Carla Maia ${ }^{1,2,4^{*}}$
}

\begin{abstract}
Background: Wildlife can act as reservoir of different tick-borne pathogens, such as bacteria, parasites and viruses. The aim of the present study was to assess the presence of tick-borne bacteria and protozoa with veterinary and zoonotic importance in cervids and wild boars from the Centre and South of Portugal.

Methods: One hundred and forty one blood samples from free-ranging ungulates including 73 red deer (Cervus elaphus), 65 wild boars (Sus scrofa) and three fallow deer (Dama dama) were tested for the presence of Anaplasma marginale/A. ovis, A. phagocytophilum, Anaplasma/Ehrlichia spp., Babesia/Theileria spp., Borrelia burgdorferi (sensu lato) (s.l.), and Rickettsia spp. DNA by PCR.
\end{abstract}

Results: Anaplasma spp. DNA was detected in 33 (43.4\%) cervids (31 red deer and two fallow deer) and in two (3.1\%) wild boars while Theileria spp. were found in 34 (44.7 \%) cervids (32 red deer and two fallow deer) and in three (4.6\%) wild boar blood samples. Sequence analysis of $m s p 4$ sequences identified $A$. marginale, $A$. ovis, while the analysis of rDNA sequence data disclosed the presence of A. platys and A. phagocytophilum and T. capreoli and Theileria sp. OT3. Anaplasma spp./Theileria spp. mixed infections were found in 17 cervids (22.4\%) and in two wild boars (3.1\%). All samples were negative for Babesia sp., B. burgdorferi (s.l.), Ehrlichia sp. or Rickettsia sp.

Conclusions: This is the first detection of Anaplasma marginale, A. ovis, A. phagocytophilum, A. platys, Theileria capreoli and Theileria sp. OT3 in cervids and wild boars from Portugal. Further studies concerning the potential pathogenicity of the different species of Anaplasma and Theileria infecting wild ungulates, the identification of their vector range, and their putative infectivity to domestic livestock and humans should be undertaken.

Keywords: Anaplasma spp., Fallow deer, PCR, Portugal, Red deer, Theileria spp., Tick-borne pathogens, Wild boar

\section{Background}

Wildlife can harbor a high density of ticks that can transmit several pathogens, such as bacteria, parasites and viruses. In addition to their veterinary importance, many of these tick-borne pathogens can also affect the human population as a result of their zoonotic potential. Therefore, the management of such situation calls for a One Health approach, including the increased awareness

\footnotetext{
* Correspondence: carlamaia@ihmt.unl.pt

${ }^{1}$ Faculty of Veterinary Medicine, Universidade Lusófona de Humanidades e Tecnologias, Lisbon, Portugal

${ }^{2}$ Global Health and Tropical Medicine (GHTM), Instituto de Higiene e Medicina Tropical (IHMT), Universidade Nova de Lisboa (UNL), Lisbon, Portugal

Full list of author information is available at the end of the article
}

for their presence especially in sylvatic environments and areas associated with animal husbandry among veterinarians, physicians and general public [1].

Piroplasmoses in cattle is caused by tick-borne protozoan parasites comprising several Theileria and Babesia species. These diseases are a serious health problem, being responsible for important economic losses to the cattle industry. In Europe, infections with different Theileria spp. [Theileria sp. OT3, T. capreoli (formerly Theileria sp. 3185/02), Theileria sp. ZS OT4, T. ovis] and Babesia spp. [including, among others, B. bigemina, $B$. capreoli, $B$. divergens and $B$. venatorum (formerly Babesia sp. EU1)] have been reported in cervids. These include fallow deer (Dama dama), red deer (Cervus elaphus) and 
roe deer (Capreolus capreolus) [2-5], while Theileria sp. and B. bigemina were detected in wild boars (Sus scrofa) [5]. In Portugal, the main pathogenic piroplasm species reported in cattle is Theileria annulata, although others, including $T$. buffeli and $T$. orientalis, considered as being moderately pathogenic or benign, are also present $[6,7]$. In addition, several pathogenic species of Babesia ( $B$. bovis, $B$. divergens and $B$. bigemina) have also been reported in cattle from central and southern Portugal $[6,7]$. Further, human babesiosis caused by $B$. divergens, B. microti or B. venatorum have been reported in several European countries [8], including one fatal case due to $B$. divergens in Portugal [9].

Anaplasmoses, caused by bacteria of the genus Anaplasma, known for a long time in veterinary medicine, are also considered as emerging human diseases, and are frequently associated with infection with Anaplasma phagocytophilum [10]. This bacterium, which is the causative agent of tick-borne fever, a disease of important negative economic impact to European animal husbandry (involving domestic ruminants), also causes human granulocytic anaplasmosis. Wild ruminants are one of its main reservoirs [11] while the role of wild boars in its natural cycle is still contradictory [12]. Other Anaplasma spp. such as A. marginale and $A$. ovis have also been detected in European cervids [13]. In Portugal, antibodies reactive to $A$. phagocytophilum antigens were detected in humans and other mammals [14], while $A$. marginale and A. ovis were detected in cattle [15] and in sheep [16], respectively.

Among the diseases caused by tick-borne pathogens, Lyme borreliosis caused by spirochetes of the Borrelia burgdorferi (sensu lato) (s.l.) complex is currently the most common tick-borne disease in Europe [17]. In Portugal, its notification in humans is mandatory, but the disease is clearly underdiagnosed and underreported [17]. Wild large vertebrates seem to be frequently exposed to these bacteria, as indicated by the detection of either Borrelia-specific antibodies in these animals or Borrelia DNA in engorged ticks collected from them $[18,19]$. Finally, several tick-borne Rickettsia spp. associated with human infections such as Rickettsia conorii, $R$. slovaca and $R$. raoultii have also been described in several European countries, including Portugal [20]. Rickettsia spp. (e.g. R. helvetica, $R$. slovaca) DNA has previously been detected in the peripheral blood [21] or in ticks removed from cervids and wild boars $[4,22]$, but the role these wild mammals play in the natural maintenance of these bacteria has not yet been clarified.

No information about tick-borne pathogens circulating in wild ungulates from Portugal is available, with the single exception of the recent detection of Borrelia burgdorferi (s.l.) in wild boars from northern Portugal [17]. Thus, the aim of the present study was to assess the presence of tick-transmitted bacteria and protozoa with veterinary and zoonotic importance in cervids and wild boars from the Centre and South of the country.

\section{Methods}

\section{Animals and samples}

During the hunting seasons, from December 2013 to March 2015, a total of 141 free-ranging ungulates including 73 red deer (Cervus elaphus), 65 wild boars (Sus scrofa) and 3 fallow deer (Dama dama) from both sexes were sampled in the districts of Castelo Branco $(n=31)$, Portalegre $(n=16)$, Lisboa $(n=19)$, Évora $(n=15)$ and Beja $(n=60)$. Animals were classified in two age categories: young (1-3 years) and adults ( $>3$ years). Blood samples were collected from each animal by cardiac or thoracic punctures in EDTA tubes and stored at $-20{ }^{\circ} \mathrm{C}$ until DNA extraction.

\section{Ethical approval}

This study was ethically approved by the board of the Faculty of Veterinary Medicine (ULHT).

\section{PCR amplification}

A commercial kit (PCR-template Preparation kit, Roche Diagnostics GmbH, Germany) was used to extract DNA from the collected blood samples, following the manufacturer's instructions.

In order to avoid false negative results due to PCR inhibition, and so as to validate the efficiency of the DNA extraction, the modified vertebrate-universal $c y t-b$ specific primers (cytB1-F and cytB2-R) were used to amplify a $350 \mathrm{bp}$ segment of the host mitochondrial cytochrome $b$ gene (cyt-b) [23]. PCR amplifications were performed in a $25 \mu \mathrm{l}$ final volume containing $12.5 \mu \mathrm{l}$ of NZYTaq 2x Green Master Mix (Nyztech, Portugal), $1 \mu \mathrm{l}$ of each primer $(10 \mathrm{pmol})$ and $2 \mu \mathrm{l}$ of template DNA.

Detection of Anaplasma/Ehrlichia spp., A. marginale/A. ovis, A. phagocytophilum, Babesia/Theileria spp., B. burgdorferi (s.l.) and Rickettsia spp. DNA in blood samples was assessed by PCR, according to previously described protocols (Table 1).

PCR amplifications were performed in a final volume of $25 \mu$ l using NZYTaq $2 \times$ Green Master Mix, $3 \mu$ of the prepared DNA extracts and $10 \mathrm{pmol}$ of each primer. In all amplifications, positive (containing genomic DNA of the targeted microrganism) and negative (without DNA) controls, were included. PCR amplifications were carried out in a Thermo Electron Corporation ${ }^{\circ}$ Px2 Termal Cycler (VWR, USA) and the obtained PCR products visualized under UV illumination after electrophoresis on $1.5 \%$ agarose gels stained with Greensafe premium ${ }^{\circ}$ (Nzytech, Portugal) using a 100 bp DNA ladder as a molecular-weight size marker (Nzytech, Portugal). 
Table 1 Sequences of the oligonucleotide primers used

\begin{tabular}{|c|c|c|c|c|c|c|}
\hline \multirow[t]{2}{*}{ Pathogen } & \multirow{2}{*}{\multicolumn{2}{|c|}{ Target gene }} & \multicolumn{2}{|l|}{ Oligonucleotide sequences $\left(5^{\prime}-3^{\prime}\right)$} & \multirow[t]{2}{*}{ Amplicon size (bp) } & \multirow[t]{2}{*}{ Reference } \\
\hline & & & Forward & Reverse & & \\
\hline \multirow[t]{2}{*}{ Anaplasma spp./Ehrlichia spp. } & \multicolumn{2}{|l|}{ 16S rRNA } & GGTACCYACAGAAGAAGTCC & TAGCACTCATCGTTTACAGC & 345 & [38] \\
\hline & \multicolumn{2}{|l|}{ groEL } & ACTGATGGTATGCARTTTGAYCG & TCTTTRCGTTCYTTMACYTCAACTTC & 600 & [39] \\
\hline Anaplasma marginale/A. centrale/A. ovis & \multicolumn{2}{|l|}{ msp4 } & GGGAGCTCCTATGAATTACAGAGAATTGTTTAC & CCGGATCCTTAGCTGAACAGGAATCTTGC & 851 & [40] \\
\hline Anaplasma phagocytophilum & \multicolumn{2}{|l|}{ msp4 } & ATGAATTACAGAGAATTGCTTGTAGG & TTAATTGAAAGCAAATCTTGCTCCTATG & 849 & [13] \\
\hline Babesia spp./Theileria spp. & \multicolumn{2}{|l|}{$18 S$ rRNA } & AATACCCAATCCTGACACAGGG & TTAAATACGAATGCCCCCAAC & 400 & [38] \\
\hline \multirow[t]{4}{*}{ Borrelia burgdorferi (sensu lato) } & \multirow[t]{2}{*}{ ITS 5S-23S rRNA } & Outer primmers & ACCATAGACTCTTATTACTTTGAC & TAAGCTGACTAATACTAATTACCC & 380 & \multirow[t]{2}{*}{ [41] } \\
\hline & & Inner primers & ACCATAGACTCTTATTACTITGACCA & GAGAGTAGGTTATTGCCAGGG & 225 & \\
\hline & \multirow[t]{2}{*}{$f l a B$} & Outer primmers & TGGTATGGGAGTTTCTGG & TAAGCTGACTAATACTAATTACCC & 774 & \multirow[t]{2}{*}[42]{} \\
\hline & & Inner primers & CAGACAACAGAGGGAAAT & TCAAGTCTATTITGGAAAGCACC & 604 & \\
\hline Rickettsia spp. & \multicolumn{2}{|l|}{$g t / A$} & GGGGGCCTGCTCACGGCGG & ATTGCAAAAAGTACAGTGAACA & 381 & [43] \\
\hline
\end{tabular}


PCR products were purified from agarose gel slices with NZYGelpure ${ }^{\circ}$ (Nzytech, Portugal) according to the manufacturer's instructions. Purified products were sent to LIGHTrun ${ }^{\text {Tx }}$ Sequencing Service (GATC-biotech, Germany) for direct sequencing of the obtained amplicons by Sanger's method with the same primers used for DNA amplification.

\section{DNA sequence analyses}

Species identity of the obtained sequences was assessed on the basis of the closest BLASTn match (identity $\geq 98 \%$ using the MegaBLAST and a query cover no smaller than $96 \%$ ) with homologous sequences deposited in the GenBank database. The sequences obtained in the course of this work were deposited at DNA Data Bank of Japan (DDBJ) (http://www.DDBJ.nig.ac.jp).

Phylogenetic relationships were inferred from nucleotide sequence alignments produced with the MAFFT multiple alignment program using a combination of the G-INS-i alignment option [24]. Phylogenetic tree construction was carried out using a Maximum Likelihood (ML) approach, using the Kimura's 2-P (K2P) evolutionary model, and assuming a $\Gamma$ distributed substitution rates among sites, as indicated by Mega6 [25] on the basis of the Akaike information criterion. Alternatively, an empirically defined model $(\mathrm{GTR}+\Gamma+\mathrm{I})$ was also used. The topological robustness of the obtained trees was assessed by bootstrapping, using 1000 resampling of the original alignment data. The final trees were manipulated for display using FigTree v.1.2.2. (available at http://tree.bio.ed.ac.uk/software/figtree/).

\section{Statistical analysis}

Percentages of positive samples for Anaplasma spp. and Theileria spp. regarding the independent variables and categories were compared by the Chi-square or Fisher's exact tests. A $P$-value $\leq 0.05$ was considered as statistically significant. Exact binomial $95 \%$ confidence intervals (CI) were defined for the proportions. Analyses were performed with Epi Info $^{\mathrm{Tm}}$ 7.1.5.2 software for Centers for Disease and Prevention.

\section{Results}

A 350 bp fragment of the host mitochondrial $c y t-b$ gene was amplified in all DNA blood samples.

Anaplasma spp. DNA was detected in 33 (43.4 \% CI: 32.1-55.3\%) cervids (31 red deer and two fallow deer) and in two (3.1 \% CI: 0.4-10.7\%) wild boars using a set of general primers that target $16 \mathrm{~S} r D N A$. Seventeen sequences obtained from red deer (accession numbers: LC126854, LC126858-9, LC126863-5, LC126867-9, LC126871, LC126873, LC126875, LC126878, LC126879 and LC126881-3) and two from wild boars (accession numbers: LC126885-6) showed 99-100 \% identity with A. platys previously described in dogs from Portugal (LC018182-3; [26]), Argentina (JX261979; [27]) and in a goat from Cyprus (EU090182; [28]). Further, eight sequences obtained from red deer (LC126855-6,

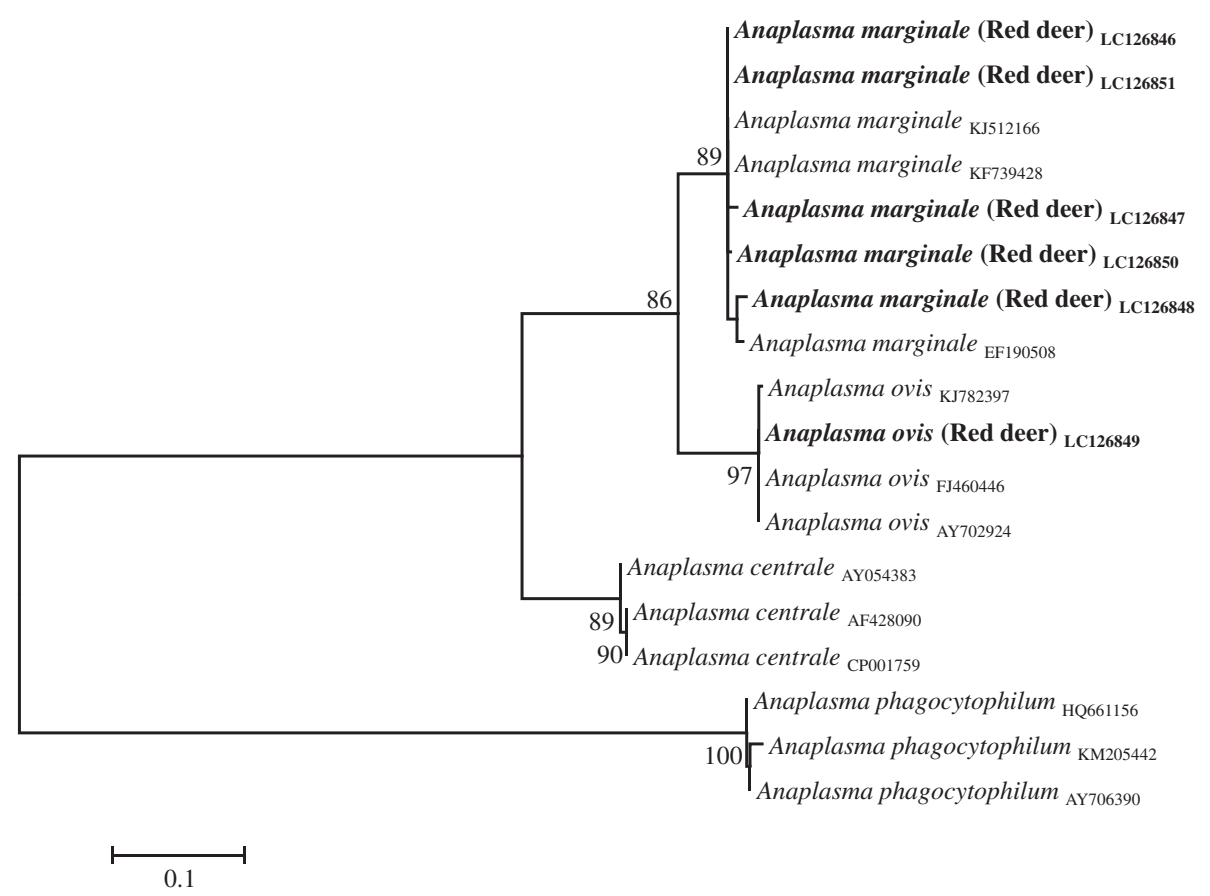

Fig. 1 Phylogenetic tree of Anaplasma spp. based on the analysis of msp4 sequences 
LC126860-2, LC126870, LC126876 and LC126884) showed $99 \%$ identity with $A$. phagocytophilum described in Swedish moose (KC800983; [29]) and in black-striped field mice (Apodemus agrarius) in South Korea (KR611719). Six sequences isolated from red deer (LC126857, LC126866, LC126872, LC126874 and LC126880) and two isolated from fallow deer (LC126852-3) showed $100 \%$ identity with A. marginale (KC335218, KC335223) described in cows and with $A$. ovis described in sheep (KC335231) and goats (KC335225) from Italy [30] as well as with $A$. centrale described in goats from China (KP062964, KP062966; [31]).

Sequencing of the msp4 gene amplified from the samples where the presence of $A$. centrale/A.marginale/ A. ovis DNA had been detected with the $16 S$ rDNA primers, confirmed the presence of $A$. marginale in five (6.6 \% CI: 2.2-14.7 \%) red deer from the Castelo Branco, Portalegre and Beja districts and A. ovis in one $(1.3 \%$ CI: 0-7.1 \%) red deer from Beja. Attempts to amplify msp4 sequences from the two fallow deer failed. The obtained $m s p 4$ sequence data, along with related sequences obtained from Genbank, were subjected to phylogenetic analyses (Fig. 1).

PCR reactions prepared using either groEL or $A$. phagocytophilum species-specific primers revealed reproducibly negative amplification results. On the contrary, Theileria spp. were found in 34 (44.7 \% CI: 33.3-56.6 \%) cervids (32 red deer and two fallow deer) and in three (4.6 \% CI: 1.0-12.9 \%) wild boar samples, using primers targeting the $18 S$ rRNA gene. Blast analysis showed that the sequences obtained from red deer (accession numbers: LC131069-100) and wild boars (LC131101-3) presented 98-99 \% identity to T. capreoli (KJ188207-8) described in Sika deer from China [32] while the two sequences obtained from fallow deer (LC131067-8) showed a high identity (98-99 \%) to the Theileria sp. OT3 (Genbank: KF470868) described in sheep from China [33]. The phylogenetical analysis of the obtained $18 S \mathrm{rDNA}$ sequences along with the related sequences from GenBank corroborated the Blast identification (Fig. 2).

Anaplasma spp./Theileria spp. co-infections were found in 17 cervids (22.4\% CI: $13.6-33.4 \%)$. Of these, eight red deer were co-infected with $A$. platys and $T$. capreoli, four with $A$. marginale and T. capreoli, two with A. phagocytophilum and T. capreoli, one with A. ovis and T. capreoli, while two fallow deer were co-infected with Anaplasma sp. and Theileria sp. OT3. Two wild boars (3.1 \% CI: 0.4$10.7 \%$ ) were co-infected with $A$. platys and T. capreoli.

The frequency of Anaplasma infection was significantly higher $(P=0.019)$ in red deer from the Castelo Branco district than from Beja (Table 2). All the blood samples taken from wild boars with positive PCR amplification results to $T$. capreoli or A. platys were from the Beja district.

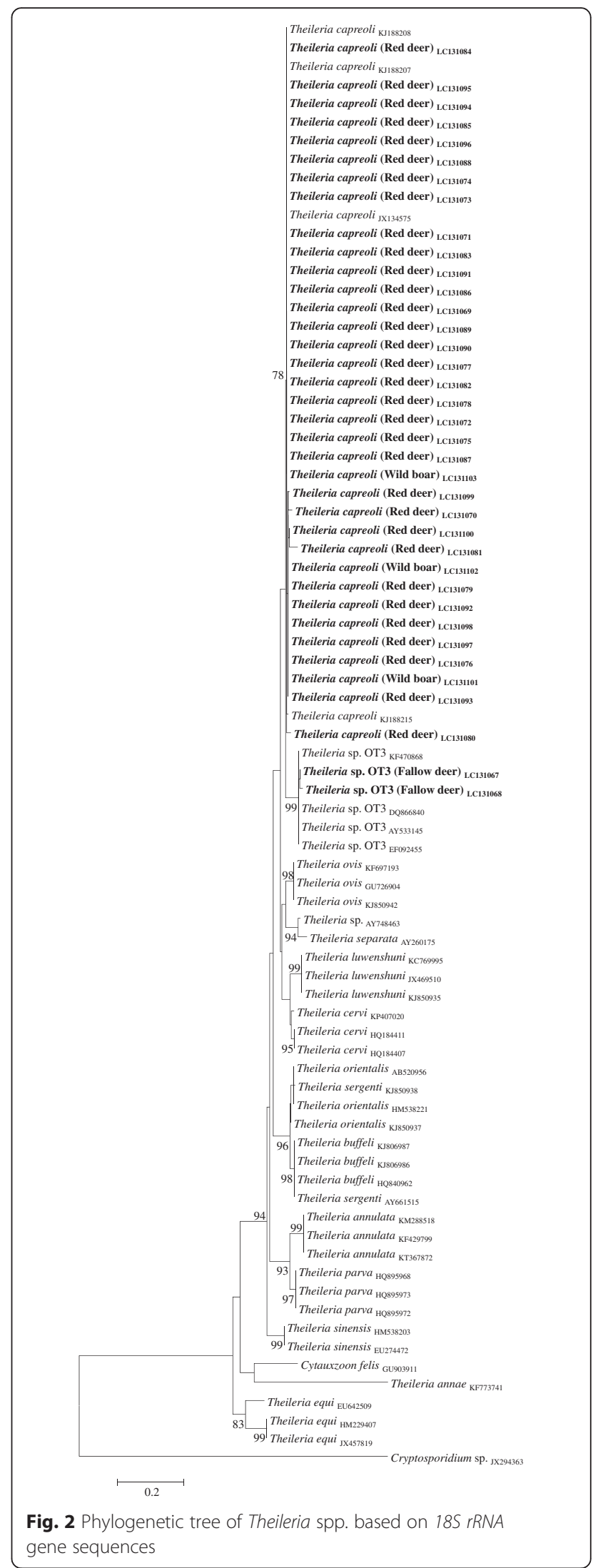

Fig. 2 Phylogenetic tree of Theileria spp. based on 185 rRNA gene sequences 
Table 2 Prevalence of tick-borne pathogens as detected by PCR in 76 cervids and 65 wild boars from Centre and southern Portugal

\begin{tabular}{|c|c|c|c|c|c|c|c|c|c|c|}
\hline \multirow[t]{3}{*}{ Idependent variable/category } & \multicolumn{5}{|c|}{ Cervus elaphus \& Dama dama } & \multicolumn{5}{|l|}{ Sus scrofa } \\
\hline & \multirow[t]{2}{*}{ No. (\%) } & \multicolumn{2}{|c|}{ Anaplasma spp. } & \multicolumn{2}{|l|}{ Theileria spp. } & \multirow[t]{2}{*}{ No. (\%) } & \multicolumn{2}{|c|}{ Anaplasma spp. } & \multicolumn{2}{|l|}{ Theileria spp. } \\
\hline & & $\%$ of positive & $95 \% \mathrm{Cl}$ & $\%$ of positive & $95 \% \mathrm{Cl}$ & & $\%$ of positive & $95 \% \mathrm{Cl}$ & $\%$ of positive & $95 \% \mathrm{Cl}$ \\
\hline District & 76 & $N D^{*}$ & & $N D^{*}$ & & 65 & $N D^{*}$ & & $N D^{*}$ & \\
\hline Castelo Branco & $27(35.5)$ & $59.3^{\mathrm{a}}$ & $38.8-77.6$ & 44.4 & $25.5-64.7$ & $4(6.2)$ & 0 & $0-60.2$ & 0.0 & $0.0-60.2$ \\
\hline Portalegre & $1(1.3)$ & 100 & $2.5-100$ & 100 & $2.5-100$ & $15(23.1)$ & 0 & $0-21.8$ & 0.0 & $0.0-21.8$ \\
\hline Lisboa & $3(3.9)$ & 66.7 & $9.4-99.2$ & 66.7 & $9.4-99.2$ & $16(24.6)$ & 0 & $0-20.6$ & 0.0 & $0.0-20.6$ \\
\hline Évora & - & - & - & - & - & $15(23.1)$ & 0 & $0-21.8$ & 0.0 & $0.0-21.8$ \\
\hline Beja & $45(59.2)$ & $31.1^{\mathrm{a}}$ & $18.2-46.7$ & 42.2 & $27.7-57.9$ & $15(23.1)$ & 13.3 & $1.66-40.5$ & 20.0 & $4.3-48.1$ \\
\hline Age & 61 & $P=0.309$ & & $P=0.607^{c}$ & & 62 & $P=1$ & & $P=0.545$ & \\
\hline Adult & $50(82.0)$ & 40.0 & $26.4-54.8$ & 46.0 & $31.8-60.7$ & $42(67.7)$ & 4.8 & $0.6-16.2$ & 7.1 & $1.5-19.5$ \\
\hline Young & $11(18.0)$ & 18.2 & $2.3-51.8$ & 54.5 & $23.4-83.3$ & $20(32.3)$ & 0 & $0-16.8$ & 0.0 & $0.0-16.8$ \\
\hline Gender & 69 & $P=0.618^{b}$ & & $P=0.025^{d}$ & & 63 & $P=0.493$ & & $P=1$ & \\
\hline Female & 37 (53.6) & 37.8 & $22.5-55.2$ & 32.4 & 18.0-49.8 & 45 (71.4) & 2.2 & $0.1-11.8$ & 4.4 & $0.5-15.2$ \\
\hline Male & $32(46.4)$ & 43.8 & $26.4-62.3$ & 59.4 & $40.7-76.3$ & 18 (28.6) & 5.6 & $0.1-27.3$ & 5.6 & $0.1-27.3$ \\
\hline Total & 76 & 43.4 & $32.1-55.3$ & 44.7 & $33.3-56.6$ & 65 & 3.1 & $0.4-10.7$ & 4.6 & $1.0-12.9$ \\
\hline
\end{tabular}

${ }^{\mathrm{a}} X^{2}=5.50, d f=1, P=0.019$

${ }^{b} X^{2}=0.25, d f=1$

$X^{2}=0.26, d f=1$

ND* Statistically significant difference(s) not confirmed after pairwise comparisons 
None of the samples analysed revealed the presence of Babesia sp., B. burgdorferi (s.l.), Ehrlichia sp. or Rickettsia sp.

\section{Discussion}

Concern about the role of wildlife in the natural maintenance transmission of tick-borne pathogens is increasing, especially in areas where free-ranging animals regularly interact with domestic livestock and humans [5, 34].

This study, which aimed at the detection of tick-borne bacteria and protozoa of veterinary and zoonotic importance in cervids and wild boars, disclosed, to our knowledge, the first evidence for the circulation of Anaplasma spp. and Theileria spp. among red deer, fallow deer and wild boars in central/southern Portugal. In this study, Anaplasma spp. infections were detected in the three wild ungulate species analysed as revealed by the amplification of $16 S$ rDNA sequences using genus-specific primers. Anaplasma platys causes canine cyclic thrombocytopenia and is presumably transmitted by ticks of the Rhipicephalus sanguineus group. As A. platys DNA has previously been reported in dogs [26], ticks [35] and red foxes [36] from Portugal, its detection in the red deer and wild boars sampled herein indicates that these animals are also exposed to the bacterium. However, the ability of $A$. platys to cause disease in these animals has not been established yet.

As wild cervids are considered one of the main reservoirs of $A$. phagocytophilum [11], the detection of this bacterium in eight red deer blood samples using $16 \mathrm{~S} r D N A$ primers it is not entirely surprising, especially when it is known that the pathogen is circulating in different Portuguese vertebrate hosts, as well as in Ixodes ricinus, its most frequently associated vector [14]. However, the absence of detection of msp4 specific sequences may indicate the circulation of divergent $A$. phagocytophilum variants among Portuguese red deer different from the ones previously reported [37]. In any case, this issue deserves future clarification. Furthermore, the presence of $A$. ovis and A. marginale in red deer was confirmed by msp4 phylogenetic analysis, confirming the susceptibility of this cervid to the agents responsible for bovine and ovine anaplasmoses [13]. Both pathogens have been reported in cattle from the Alentejo region (which includes the Évora and Beja districts [15]), and in sheep raised throughout the country [16].

The occurrence of Theileria spp. infections in European cervids is well documented [2-5]. In the present study, and for the first time in Portugal, T. capreoli and Theileria sp. OT3 msp4 sequences were amplified from red deer and fallow deer samples, respectively, corroborating previous data from northern Spain [3]. The overall prevalence of Babesia spp. and Theileria spp. infections previously reported in cattle from the central and southern regions of Portugal ranged from $23.1 \%$ [7] to $74.7 \%$
[6], respectively, with $T$. annulata and T. buffeli being the most commonly detected species and B. bigemina, $B$. bovis and $B$. divergens being the least frequently found. As none of the Theileria and Babesia species known to circulate in the Portuguese cattle were detected in the present study, it seems that the tested wild ungulate species might not play a significant role in their transmission, at least in the regions where samples were collected. Furthermore, although deer have been previously appointed as the source for ovine infection with Theileria sp. OT3 [3], no data is yet available regarding the circulation of piroplasmids in small ruminants from Portugal.

Despite the fact that B. burgdorferi (s.l.) and Rickettsia spp. have already been detected in ticks and/or in the blood collected from cervids and wild boars [4, 17, 19, $22]$, their presence was not revealed in any of the samples analysed in the present study. This observation supports the hypothesis that wild ungulates, at least in the studied areas, are not pivotal players in the natural maintenance cycles of these bacteria, as previously reported $[4,21]$.

As large wildlife are important to maintain tick populations, and since ticks may become infected with several pathogens during their life cycle, the detection of Anaplasma spp./Theileria spp. co-infections in the present study is not surprising, and falls in line with previously published observations in wild ungulates [4]. The interaction of different pathogens within the vertebrate host might lead to increased susceptibility to other infections as well as a modification of the pathogenesis of each microorganism with profound consequences for disease management programs and wildlife conservation [4].

\section{Conclusions}

The present study provides information regarding the presence of Anaplasma marginale, A. ovis, A. phagocytophilum, A. platys, Theileria capreoli and Theileria sp. OT3 in cervids and wild boars from central and southern Portugal. Further studies concerning the potential pathogenicity of the different Anaplasma and Theileria species infecting wild ungulates, the identification of their vector range, and their infectivity to domestic livestock and humans should be undertaken.

\section{Competing interests}

The authors declare that they have no competing interests.

Authors' contributions

AP performed DNA extraction, PCR assays and data analysis; RP performed DNA sequence analysis and revised the manuscript; MN performed B. burgdorferi s.l. nested-PCRs; AC collected blood samples and animal data; MLV and LC reviewed the manuscript: CM planned, designed and supervised the study, and wrote the manuscript; All authors read and approved the final manuscript. 


\section{Acknowledgments}

The authors wish to acknowledge FCT for funds to GHTM - UID/Multi/04413/ 2013 and the hunters for their assistance in obtaining the blood samples and B. Almeida and G. Acto for technical assistance. M. Nunes was supported by the Ministry of Education and Science of Portugal, Fundação para a Ciência e a Tecnologia, through a PhD grant (SFRH/BD/78325/2011). The work of C. Maia was done under the frame of EurNegVec COST Action TD1303.

Publication of this paper has been sponsored by Bayer HealthCare - Animal Health Division in the framework of the 11th CVBD World Forum Symposium.

\section{Author details}

${ }^{1}$ Faculty of Veterinary Medicine, Universidade Lusófona de Humanidades e Tecnologias, Lisbon, Portugal. ${ }^{2}$ Global Health and Tropical Medicine (GHTM), Instituto de Higiene e Medicina Tropical (IHMT), Universidade Nova de Lisboa (UNL), Lisbon, Portugal. ${ }^{3}$ Medical Microbiology Unit, IHMT, UNL, Lisbon, Portugal. ${ }^{4}$ Medical Parasitology Unit, IHMT-UNL, Lisbon, Portugal. ${ }^{5}$ Department of Biomdical Scienecs and Medicine, Universidade do Algarve, Lisbon, Portugal.

\section{Received: 6 April 2016 Accepted: 25 April 2016 Published online: 10 May 2016}

\section{References}

1. Dantas-Torres F, Chomel BB, Otranto D. Ticks and tick-borne diseases: a One Health perspective. Trends Parasitol. 2012;28:437-46.

2. Duh D, Petrovec M, Bidovec A, Avsic-Zupanc T. Cervids as babesiae hosts, Slovenia. Emerg Infect Dis. 2005;11:1121-3.

3. García-Sanmartín J, Aurtenetxe O, Barral M, Marco I, Lavin S, García-Pérez AL, et al. Molecular detection and characterization of piroplasms infecting cervids and chamois in Northern Spain. Parasitology. 2007;134:391-8.

4. Overzier E, Pfister K, Herb I, Mahling M, Böck G, Silaghi C. Detection of tick-borne pathogens in roe deer (Capreolus capreolus), in questing ticks (Ixodes ricinus), and in ticks infesting roe deer in southern Germany. Ticks Tick Borne Dis. 2013;4:320-8.

5. Zanet S, Trisciuoglio A, Bottero E, de Mera IG, Gortazar C, Carpignano MG, et al. Piroplasmosis in wildlife: Babesia and Theileria affecting free-ranging ungulates and carnivores in the Italian Alps. Parasit Vectors. 2014;7:70.

6. Silva MG, Marques PX, Oliva A. Detection of Babesia and Theileria species infection in cattle from Portugal using a reverse line blotting method. Vet Parasitol. 2010;174:199-205

7. Gomes J, Soares R, Santos M, Santos-Gomes G, Botelho A, Amaro A, et al. Detection of Theileria and Babesia infections amongst asymptomatic cattle in Portugal. Ticks Tick Borne Dis. 2013;4:148-51.

8. Yabsley MJ, Shock BC. Natural history of Zoonotic Babesia: Role of wildlife reservoirs. Int J Parasitol Parasites Wildl. 2013;2:18-31.

9. Centeno-Lima S, do Rosário V, Parreira R, Maia AJ, Freudenthal AM, Nijhof AM, et al. A fatal case of human babesiosis in Portugal: molecular and phylogenetic analysis. Trop Med Int Health. 2003;8:760-4.

10. Doudier B, Olano J, Parola P, Brouqui P. Factors contributing to emergence of Ehrlichia and Anaplasma spp. as human pathogens. Vet Parasitol. 2010;167:149-54

11. Stuen S, Granquist EG, Silaghi C. Anaplasma phagocytophilum-a widespread multi-host pathogen with highly adaptive strategies. Front Cell Infect Microbiol. 2013;3:31.

12. de la Fuente J, Gortazar C. Wild boars as hosts of human-pathogenic Anaplasma phagocytophilum variants. Emerg Infect Dis. 2012;18:2094-5.

13. de la Fuente J, Massung RF, Wong SJ, Chu FK, Lutz H, Meli M, et al. Sequence analysis of the msp4 gene of Anaplasma phagocytophilum strains. J Clin Microbiol. 2005;43:1309-17.

14. Santos AS, Bacellar F, Dumler JS. A 4-year study of Anaplasma phagocytophilum in Portugal. Clin Microbiol Infect. 2008;15:46-7.

15. Gomes J, Rebêlo E. Seroprevalência da anaplasmose bovina em Portugal. In: Abstract book - IV Veterinary Sciences Congress. Portugal: Portuguese Society of Veterinary Sciences; 2008. p. 211.

16. Renneker S, Abdo J, Salih DE, Karagenç T, Bilgiç H, Torina A, et al. Can Anaplasma ovis in small ruminants be neglected any longer? Transbound Emerg Dis. 2013;60:105-12.

17. Faria AS, Paiva-Cardoso MD, Nunes M, Carreira T, Vale-Gonçalves HM, Veloso O, et al. First Detection of Borrelia burgdorferi sensu lato DNA in Serum of the Wild Boar (Sus scrofa) in Northern Portugal by Nested-PCR. Ecohealth. 2015;12:183-7.
18. Doby JM, Betremieux C, Rolland C, Barrat J. The large forest mammals reservoirs for Borrelia burgdorferi, agent of the Lyme disease? Serological examination of 543 deers and wild-boars. Rec Med Vet Ec Alfort. 1991;167:55-61.

19. Wodecka B, Rymaszewska A, Skotarczak B. Host and pathogen DNA identification in blood meals of nymphal Ixodes ricinus ticks from forest parks and rural forests of Poland. Exp Appl Acarol. 2014;62:543-55.

20. Oteo JA, Portillo A. Tick-borne rickettsioses in Europe. Ticks Tick Borne Dis. 2012;3:271-8.

21. Stefanidesova K, Kocianova E, Boldis V, Kostanova Z, Kanka P, Nemethova D, et al. Evidence of Anaplasma phagocytophilum and Rickettsia helvetica infection in free-ranging ungulates in central Slovakia. Eur J Wildl Res. 2008:54:519-24

22. Sprong $H$, Wielinga PR, Fonville $M$, Reusken $C$, Brandenburg AH, Borgsteede $F$, et al. Ixodes ricinus ticks are reservoir hosts for Rickettsia helvetica and potentially carry flea-borne Rickettsia species. Parasit Vectors. 2009;2:41

23. Maia C, Parreira R, Cristóvão JM, Freitas FB, Afonso MO, Campino L. Molecular detection of Leishmania DNA and identification of blood meals in wild caught phlebotomine sand flies (Diptera: Psychodidae) from southern Portugal. Parasit Vectors. 2015;8:173.

24. Katoh $\mathrm{K}$, Toh $\mathrm{H}$. Recent developments in the MAFFT multiple sequence alignment program. Brief Bioinform. 2008;9:286-98.

25. Tamura K, Stecher G, Peterson D, Filipski A, Kumar S. MEGA6: Molecular Evolutionary Genetics Analysis version 6.0. Mol Biol Evol. 2013;30:2725-9.

26. Maia C, Almeida B, Coimbra M, Fernandes MC, Cristóvão JM, Ramos C, et al. Bacterial and protozoal agents of canine vector-borne diseases in the blood of domestic and stray dogs from southern Portugal. Parasit Vectors. 2015:8:759.

27. Eiras DF, Craviotto MB, Vezzani D, Eyal O, Baneth G. First description of natural Ehrlichia canis and Anaplasma platys infections in dogs from Argentina. Comp Immunol Microbiol Infect Dis. 2013;36:169-73.

28. Chochlakis D, loannou I, Sharif L, Kokkini S, Hristophi N, Dimitriou T, et al. Prevalence of Anaplasma sp. in goats and sheep in Cyprus. Vector Borne Zoonotic Dis. 2009;9:457-63.

29. Malmsten J, Widén DG, Rydevik G, Yon L, Hutchings MR, Thulin CG, et al. Temporal and spatial variation in Anaplasma phagocytophilum infection in Swedish moose (Alces alces). Epidemiol Infect. 2014;142:1205-13.

30. Zobba R, Anfossi AG, Pinna Parpaglia ML, Dore GM, Chessa B, Spezzigu A, et al. Molecular Investigation and Phylogeny of Anaplasma spp. Mediterranean Ruminants Reveal the Presence of Neutrophil-Tropic Strains Closely Related to A. platys. Appl Environ Microbiol. 2014;80:271-80.

31. Yan G, Hongmei Y, Yasuko R, Weiqing P, Hong Y. Molecular detection of tick-borne rickettsiales in goats and sheep from southeastern China. Vector Borne Zoonotic Dis. 2016. doi:10.1089/vbz.2015.1884.

32. Li Y, Chen Z, Liu Z, Liu J, Yang J, Li Q, et al. Molecular identification of Theileria parasites of northwestern Chinese Cervidae. Parasit Vectors. 2014:7:225.

33. Tian Z, Liu G, Yin $H$, Xie J, Wang S, Yuan $X$, et al. First report on the occurrence of Theileria sp. OT3 in China. Parasitol Int. 2014;63:403-7.

34. de la Fuente J, Estrada-Pena A, Venzal JM, Kocan KM, Sonenshine DE. Overview: Ticks as vectors of pathogens that cause disease in humans and animals. Front Biosci. 2008;13:6938-46.

35. Maia C, Ferreira A, Nunes M, Vieira ML, Campino L, Cardoso L. Molecular detection of bacterial and parasitic pathogens in hard ticks from Portugal. Ticks Tick Borne Dis. 2014:5:409-14.

36. Cardoso L, Gilad M, Cortes HC, Nachum-Biala Y, Lopes AP, Vila-Viçosa MJ, et al. First report of Anaplasma platys infection in red foxes (Vulpes vulpes) and molecular detection of Ehrlichia canis and Leishmania infantum in foxes from Portugal. Parasit Vectors. 2015;8:144.

37. Stuen S, Pettersen KS, Granquist EG, Bergström K, Bown KJ, Birtles RJ. Anaplasma phagocytophilum variants in sympatric red deer (Cervus elaphus) and sheep in southern Norway. Ticks Tick Borne Dis. 2013;4:197-201.

38. Harrus S, Perlman-Avrahami A, Mumcuoglu KY, Morick D, Eyal O, Baneth G. Molecular detection of Ehrlichia canis, Anaplasma bovis, Anaplasma platys, Candidatus Midichloria mitochondrii and Babesia canis vogeli in ticks from Israel. Clin Microbiol Infect. 2011:17:459-63.

39. Barber R, Li Q, Diniz P, Porter B, Breitschwerdt E, Claiborne M, et al. Evaluation of brain tissue or cerebrospinal fluid with broadly reactive polymerase chain reaction for Ehrlichia, Anaplasma, spotted fever group Rickettsia, Bartonella, and Borrelia species in canine neurological diseases (109 cases). J Vet Intern Med. 2010;24:372-8. 
40. de la Fuente J, Van Den Bussche RA, Prado TM, Kocan KM. Anaplasma marginale msplalpha genotypes evolved under positive selection pressure but are not markers for geographic isolates. J Clin Microbiol. 2003;41:1609-16.

41. Schwartz JJ, Gazumyan A, Schwartz I. rRNA gene organization in the Lyme disease spirochete, Borrelia burgdorferi. J Bacteriol. 1992;174:3757-65.

42. Wodecka B, Leońska A, Skotarczak B. A comparative analysis of molecular markers for the detection and identification of Borrelia spirochaetes in Ixodes ricinus. J Med Microbiol. 2010;59:309-14.

43. Regnery RL, Spruill CL, Plikaytis BD. Genotypic identification of rickettsiae and estimation of intraspecies sequence divergence for portions of two rickettsial genes. J Bacteriol. 1991;173:1576-89.

Submit your next manuscript to BioMed Central and we will help you at every step:

- We accept pre-submission inquiries

- Our selector tool helps you to find the most relevant journal

- We provide round the clock customer support

- Convenient online submission

- Thorough peer review

- Inclusion in PubMed and all major indexing services

- Maximum visibility for your research

Submit your manuscript at www.biomedcentral.com/submit
Biomed Central 